\title{
Skinning the cat: Another wrinkle for T-tube insertion
}

\author{
Cameron D. Wright, MD
}

\author{
From the Division of Thoracic Surgery, Massachusetts General Hospital, Boston, Mass. \\ Disclosures: Author has nothing to disclose with regard to commercial support. \\ Received for publication Oct 20, 2017; accepted for publication Oct 27, 2017; available ahead of print Dec 13, \\ 2017. \\ Address for reprints: Cameron D. Wright, MD, Division of Thoracic Surgery, Massachusetts General Hospital, 55 \\ Fruit St, Boston, MA 02114 (E-mail: cdwright@mgh.harvard.edu). \\ J Thorac Cardiovasc Surg 2018;155:1915-6 \\ $0022-5223 / \$ 36.00$ \\ Copyright (C 2017 by The American Association for Thoracic Surgery \\ https://doi.org/10.1016/j.jtcvs.2017.10.121
}

Subglottic stenosis and tracheal stenosis have many treatment options if the patient is not a candidate for a definitive repair. Dilation, with or without adjunctive radial laser cuts, can be used as a temporizing measure, or sometimes as a more definitive procedure with mature scar. Stenting is necessary when the patient does not respond to dilation, either from quick recurrent obstruction or because of a stenosis that does not open up with dilation. Self-expanding metal stents are not appropriate for benign strictures because of problems with infection and with granulation ingrowth at both ends. Silicone stents are therefore usually used, and they can be self-retaining or the T-tube type. T tubes have the advantage of easy access to the airway through the horizontal limb of the tube, which also serves as an anchor to prevent tube migration. T tubes are usually straightforward to change and rarely incite troublesome granulation tissue. They are usually changed on a yearly basis, because a biofilm does build up, which can lead to infections and poor clearance of respiratory secretions. The main disadvantage of the $\mathrm{T}$ tube is the requirement of a tracheal stoma for insertion, with the resulting horizontal limb with cap protruding from the neck of the patient. T tubes are made by several commercial companies and come in a large variety of sizes and lengths. They are easily customizable in the operating room simply by cutting the proximal and distal limbs to the required length. The proximal limb should be several millimeters below the vocal cords to avoid interfering with voice quality and to avoid granulation tissue ingrowth.

The typical postintubation tracheal stenosis is a cuff stenosis just below the tracheostomy stoma. In this case, T-tube insertion is usually very easy, and the superior vertical limb easily is positioned into the subglottic space. When there is subglottic stenosis, however, it can be very challenging to seat the proximal limb of the $\mathrm{T}$ tube properly. Obviously, the subglottic stricture must be dilated first. As Fiorelli and colleagues ${ }^{1}$ note in their article in this issue of the Journal, a few reports have suggested other methods to facilitate proper positioning of the superior limb of the $\mathrm{T}$ tube. My personal favorite is the use of umbilical tape passed through the horizontal limb into the superior limb, which is

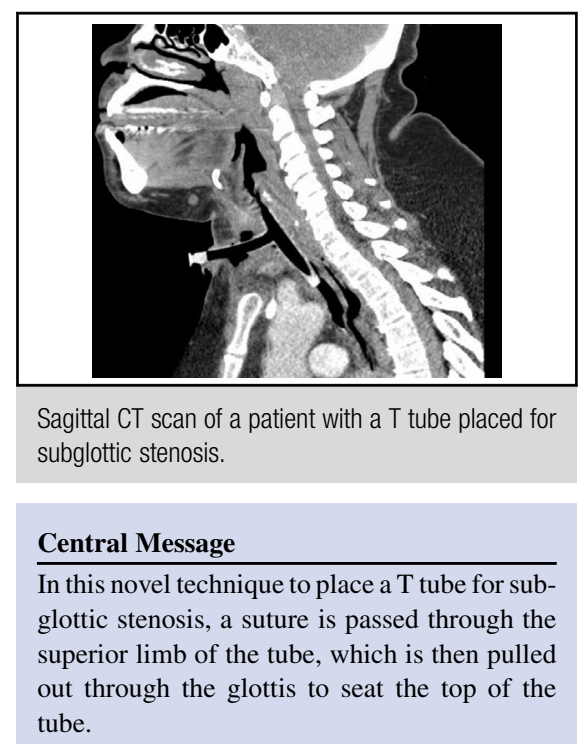

See Article page 1912.

then grasped with forceps from the subglottic space and pulled out from the mouth. Pulling on the tape with the force directed superiorly helps to seat the tube superiorly after the distal vertical limb is passed well into the trachea. This method was first described by Cooper and associates. ${ }^{2}$

Here, Fiorelli and colleagues ${ }^{1}$ report another technique to seat the superior limb of the T tube properly into the subglottic space. A suture passed through the wall of the superior vertical limb is used to pull the top of the tube into the subglottic space. One potential problem that I see with this approach is possible tearing of the silicone tube, which could either lead to the need to place another tube or cause a problem later on if left in place. Obviously, judicious pulling and dilation of the subglottic stenosis are required for success with this technique. Cooper and colleagues ${ }^{3}$ also described 2 other possible techniques for T-tube insertion that were modified from a technique described by Duval and Bauer. ${ }^{4}$ One involved using a small rigid bronchoscope with a balloon on the end, which would anchor the tube onto the rigid bronchoscope until it was passed into the airway. The balloon would be deflated and the rigid bronchoscope removed, leaving the $\mathrm{T}$ tube in place. The problem of orienting and pulling the horizontal limb out of the stoma was solved by tying a suture around the tip of the horizontal limb beforehand and then passing it down through the subglottic space and pulling it out of the stoma. The suture was then pulled when the horizontal limb was at the stoma level to seat it. Alternatively, the $\mathrm{T}$ tube was loaded onto a 
small bronchoscope, again with an endotracheal tube behind it to use as a pusher to hold the $\mathrm{T}$ tube in place once it was properly positioned as the bronchoscope was withdrawn. An innovative surgeon might modify the technique further by tying a suture around the superior horizontal limb of the $\mathrm{T}$ tube (instead of piercing it with a suture) to pull it into the subglottic space, thus minimizing the risk of tearing the $\mathrm{T}$ tube. So there are many ways to skin the cat, and prudent surgeons will find one or two ways that work best for them.

\section{References}

1. Fiorelli A, Carlucci A, Pota V, Santini M. A simplified insertion technique for tracheal T tube. J Thorac Cardiovasc Surg. 2018;155:1912-4.

2. Cooper JD, Todd TR, Ilves R, Pearson FG. Use of the silicone T tube for the management of complex tracheal injuries. J Thorac Cardiovasc Surg. 1981;82: 559-68.

3. Cooper JD, Pearson FG, Patterson GA, Todd TR, Ginsberg RJ, Goldberg M, et al. Use of silicone stents in the management of airway problems. Ann Thorac Surg. 1989;47:371-8.

4. Duval AJ, Bauer W. An endoscopically introducible T-tube for tracheal stenosis. Laryngoscope. 1977;87:2031-7. 